\title{
QUALIDADE DA ÁGUA E PRESENÇA DE ECTOPARASITOS EM ALEVINOS DE TILÁPIA (OREOCHROMIS NILOTICUS)
}

\author{
WATER QUALITY AND PRESENCE IN FRY ECTOPARASITES \\ (OREOCHROMIS NILOTICUS)
}

V. C. M. SILVA ${ }^{1}$, J. DIAS NETO ${ }^{2}$, P. M. P. BRANCO ${ }^{1}$, L. A. AMARAL ${ }^{1}$

\begin{abstract}
RESUMO
Com a intensificação da produção inevitavelmente ocorre maior incidência de doenças e, consequentemente, observa-se o aumento da demanda por um controle higiênico-sanitário a partir da implantação de medidas que evitam a entrada de patógenos, além de controlar a disseminação às outras unidades de produção. $\mathrm{O}$ trabalho teve como objetivo verificar a qualidade da água e a presença de ectoparasitas em alevinos de Tilápia do Nilo (Oreochromis niloticus). Foram realizados os monitoramentos de água dos tanques, sendo medidos em pontos distintos os parâmetros de temperatura, oxigênio dissolvido, condutividade elétrica e pH por meio de sonda multiparametrica (YSI Profissional Plus). Por colheita foram analisados 10 peixes de cada tanque, com auxílio de um puçá e posteriormente foram realizados exames visuais externos nos olhos, boca, opérculo, brânquias, tegumentos e nadadeiras. Foram realizados exames parasitológicos pela técnica de deslocamento da primeira vértebra cervical para coleta de muco tegumentar e biopsia branquial. Todos parâmetros físicoquímicos da água estavam dentro dos padrões para produção de peixes. Porém quando comparado a qualidade da água do sistema de produção e do reservatório de abastecimento foi demonstrado que a condutividade, que representa a concentração de matéria orgânica do meio, alterou consideravelmente. Seguindo a mesma tendência, o índice de parasitos, principalmente representado pelos Tricodinídeos, aumentou quando os níveis de nutrientes dissolvidos se encontravam mais altos. Com um conjunto de medidas sanitárias que compõe o programa de monitoramento sanitário foi observado que a partir do quinto mês de monitoramento, embora a condutividade tenha voltado a subir, as incidências de parasitos se mantiveram baixas. A geração e armazenamento de dados em um programa sanitário, torna-se necessário para se seja mais precisa a identificação da origem de um problema e com isso a implantação de um protocolo de biossegurança para que seja feito o monitoramento da piscicultura.
\end{abstract}

PALAVRAS-CHAVE: BIOSSEGURANÇA, CONTROLE PARASITÁRIO, SANIDADE AQUÍCOLA

AGRADECIMENTOS: Prevet Sanidade Aquícola

ÁREA TEMÁTICA: 5- Saúde Pública

\footnotetext{
${ }^{1}$ Faculdade de Ciências Agrárias e Veterinárias da Universidade Estadual Paulista (UNESP) - Câmpus de Jaboticabal

* vansilva022011@gmail.com

${ }^{2}$ Prevet Sanidade Aquícola, Jaboticabal - SP
} 